\title{
Rancangan Alat Pendeteksi Benda dengan Berdasarkan Warna, Bentuk, dan Ukuran dengan Webcam
}

\author{
Ali Basrah Pulungan ${ }^{1}$, dan Zhafranul Nafis ${ }^{2}$ \\ 1,2 Jurusan Teknik Elektro, Fakultas Teknik, Universitas Negeri Padang \\ Jl. Prof Dr. Hamka Air Tawar 25171, Padang, Indonesia \\ Email : alibp@ft.unp.ac.id, zhafranulnafis19@gmail.com
}

\begin{abstract}
Along with the times, technology is also developing so rapidly, one of the innovations in technological development is the use of webcams. the use of a webcam can be developed as a sensor in detecting an object through several stages of image processing. The use of a webcam aims to simplify an automation system so that it can be used to perform several tasks at once. Therefore, the author intends to design and manufacture an object detector with measurement parameters of the object's color, shape and size. This tool uses a webcam as a sensing sensor, and uses programming in PYTHON to recognize objects to be detected, and uses a servo motor to drive object actuators. The results of this tool have been tested and are able to detect objects properly based on predetermined color, shape and size. This tool is also able to separate objects that meet specifications from objects that do not meet specifications. Object detection using a webcam and an object separating actuator can work well.
\end{abstract}

Keywords: Webcam, Python, Servo Motor, Image Processing, Automation.

Abstrak - Seiring perkembangan zaman, teknologi juga berkembang begitu pesat, salah satu inovasi dalam perkembangan teknologi adalah pemanfaatan webcam. pemanfaatan webcam dapat dikembangkan sebagai sensor dalam mendeteksi sebuah benda melalui beberapa tahap pengolahan citra. Penggunaan webcam bertujuan untuk penyederhanaan sebuah sistem otomasi agar dapat digunakan untuk melakukan beberapa tugas sekaligus. oleh karena itu penulis bermaksud untuk merancang dan membuat alat pendeteksi benda dengan parameter pengukuran warna, bentuk, dan ukuran benda. Pada alat ini menggunakan webcam sebagai sensor pengindraan, dan menggunakan pemrograman dalam PYTHON untuk proses pengenalan benda yang akan di deteksi, dan menggunakan motor servo untuk aktuator pendorong benda. Hasil dari alat ini sudah diuji dan mampu mendeteksi benda dengan baik berdasarkan warna, bentuk, dan ukuran yang sudah ditentukan. Alat ini juga mampu memisahkan antara benda yang sesuai spesifikasi dengan benda yang tidak sesuai spesifikasi. Deteksi benda menggunakan webcam dan actuator pemisah benda dapat bekerja dengan baik.

Kata kunci: Webcam, Python, Motor Servo, Pengolahan Citra, Otomasi.

\section{Pendahuluan}

Seiring perkembangan zaman, teknologi juga berkembang begitu pesat, berbagai macam cara dilakukan untuk mempermudah manusia dalam melakukan suatu pekerjaan, salah satunya yaitu dengan memanfaatkan kecerdasan buatan[1], banyak orang-orang berlomba untuk membuat inovasi baru untuk dapat menciptakan alat yang dapat lebih mempermudah pekerjaan.

Salah satu inovasi dalam perkembangan teknologi adalah pemanfaatan webcam. Sekarang ini webcam sudah banyak digunakan di industri, mulai dari untuk kontrol kualitas, sortir, keamanan[2],selain itu juga dapat dikembangkan sebagai sensor dalam mendeteksi sebuah benda melalui beberapa tahap pengolahan citra[1].

Teknologi ini umumnya digunakan sebagai alat sortir benda dalam dunia industri yang berskala besar, semakin kompleks sistem otomasi penyortiran maka akan semakin banyak sensor yang dibutuhkan, dan hal ini memungkinkan terjadinya banyak kesalahan[3].
Jika ada sebuah sensor yang dapat digunakan untuk melakukan beberapa tugas sekaligus sehingga jumlah sensor yang digunakan dapat dikurangi[3], sehingga kemungkinan terjadi kegagalan pendeteksian salah satu parameter pengukuran akan berkurang.

Pada beberapa penelitian sebelumnya hanya menggunakan dua parameter untuk pengenalan benda, yaitu pengenalan bentuk-warna, dan pengenalan warnaukuran, akan lebih efektif jika pengenalan benda menggunakan tiga parameter pengenalan benda sekaligus, yaitu warna, bentuk, dan ukuran, agar proses sortir benda lebih selektif.

Oleh karena itu penulis bermaksud untuk merancang dan membuat alat pendeteksi benda dengan parameter pengukuran warna, bentuk, dan ukuran pada suatu benda dengan menggunakan webcam sebagai sensor penginderaannya, dan citra atau gambar yang ditangkap webcam akan di proses dalam PYTHON. Dengan actuator pemindah benda dari penampungan ke tempat 
pendeteksian menggunakan servo $360^{\circ}$ dan actuator pemisah benda yang sesuai spesifikasi dengan yang tidak sesuai menggunakan servo $180^{\circ}$.

\section{Citra}

Citra digital adalah gambar dua dimensi yang dapat ditampilkan pada layar monitor computer sebagai himpunan berhingga (diskrit) nilai digital yang disebut pixel (picture elements). Pixel adalah elemen citra yang memiliki nilai yang menunjukkan intensitas warna[4], pengolahan citra yaitu proses untuk mengolah suatu kualitas gambar atau citra yang telah diambil kamera atau webcam agar gambar tersebut dapat dikenali dan memiliki nilai-nilai tertentu. Nilai-nilai yang telah didapat kemudian diproses untuk mengklasifikasikan gambar-gambar tersebut.

Pengolahan citra untuk pengenalan warna adalah segmentasi warna RGB ke HSV, yaitu proses seleksi warna dengan pemilihan sampel piksel sebagai acuan warna untuk membentuk segmen yang diinginkan [5], kemudian proses tersebut akan membentuk segmen area dengan warna sesuai toleransi yang diinginkan[6], selain itu juga ada proses Thresholding yang merupakan konversi citra berwarna ke citra biner yang dilakukan dengan cara mengelompokkan nilai derajat keabuan setiap pixel kedalam 2 kelas, hitam dan putih, pada operasi pengambangan, nilai intensitas pixel dipetakan ke salah satu dari dua nilai, $\alpha_{1}$ atau $\alpha_{2}$ [7], dan kontur adalah keadaan yang ditimbulkan oleh perubahan intensitas pada pixel-pixel yang berbeda. Karena adanya perubahan intensitas inilah maka terdeteksi tepi-tepi (edge) objek di dalam citra[8].

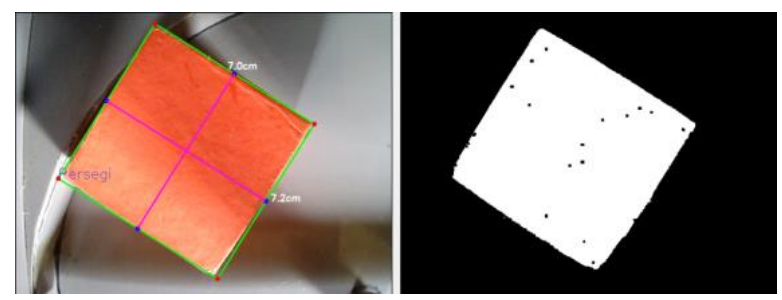

Gambar 1, Pengolahan Citra.

Pada gambar diatas adalah hasil dari pengolahan citra dengan proses segmentasi warna HSV dan thresholding, dimana warna merah termasuk dalam warna yang ditentukan sehingga warna dapat dikenali, dan hasil dari segmentasi warna tersebut dijadikan gambar biner dengan proses thresholding.

\section{PYTHON}

Python adalah bahasa pemrograman interpretatif multiguna yang mudah untuk dibaca dan dipahami, python lebih menekankan pada keterbacaan kode agar lebih mudah untuk memahami sintaks. Dengan kode yang simpel dan mudah diimplementasikan membuat Python sangat mudah dipelajari baik untuk pemula maupun untuk yang sudah menguasai bahasa pemrograman.

\section{Arduino UNO}

Arduino UNO adalah papan mikrokontroler opensource berbasis mikrokontroler Microchip ATmega328P, Arduino mempunyai bahasa pemrograman sendiri yang berupa bahasa C, dalam board arduino sendiri sudah terdapat loader yang berupa USB yang mempermudah untuk memprogram arduino.

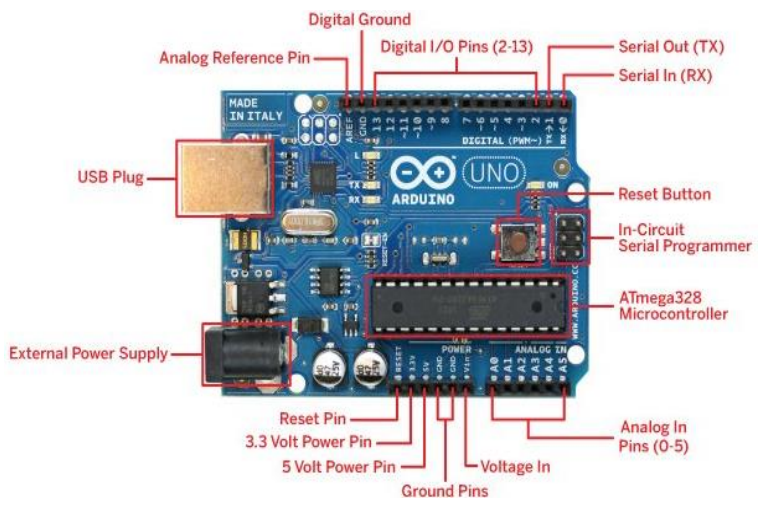

Gambar 2. Arduino UNO

\section{Webcam}

Webcam yang pada tugas akhir ini berfungsi untuk melakukan capture benda yang akan di deteksi, dan output dari gambar data yang dimiliki akan diolah menggunakan aplikasi PYTHON.

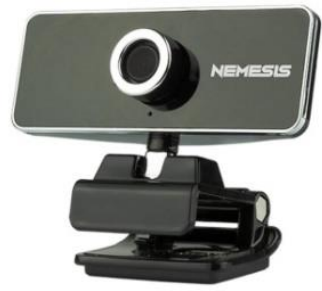

Gambar 3. Webcam

\section{Sensor Infrared(IR)}

Sensor infra merah adalah sensor yang bekerja jika sinar infra merah yang dipancarkan terhalang oleh suatu benda yang mengakibatkan sinar infra merah tersebut tidak dapat terdeteksi oleh penerima. sehingga penerima langsung mengubah frekuensi tersebut menjadi logika 0 dan 1. Jika detektor inframerah menerima frekuensi carrier tersebut, maka pin keluarannya akan berlogika 0 . Sebaliknya, jika tidak menerima frekuensi carrier tersebut, maka keluaran detektor inframerah akan berlogika 1 .

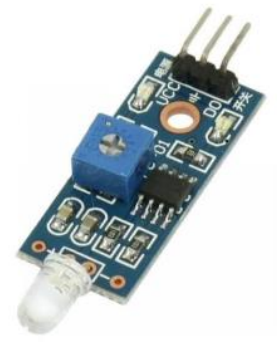

Gambar 4. Sensor Photodioda 


\section{Motor Servo}

Motor Servo merupakan motor listrik dengan menggunakan sistem closed loop. Pada umumnya motor servo terdiri dari tiga komponen utama yaitu motor berfungsi sebagai penggerak roda gigi agar dapat memutar potensiometer dan poros output-nya secara bersamaan, potensiometer atau encoder berfungsi sebagai sensor yang akan memberikan sinyal umpan balik ke sistem kontrol untuk menentukan posisi targetnya.

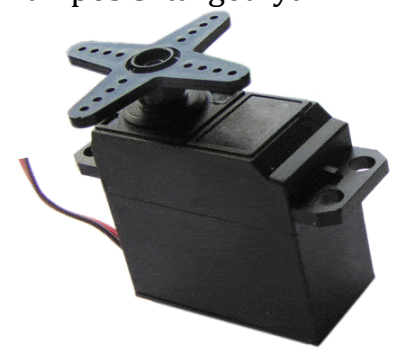

Gambar 5, Motor Servo

\section{Metode}

\section{Blog Diagram}

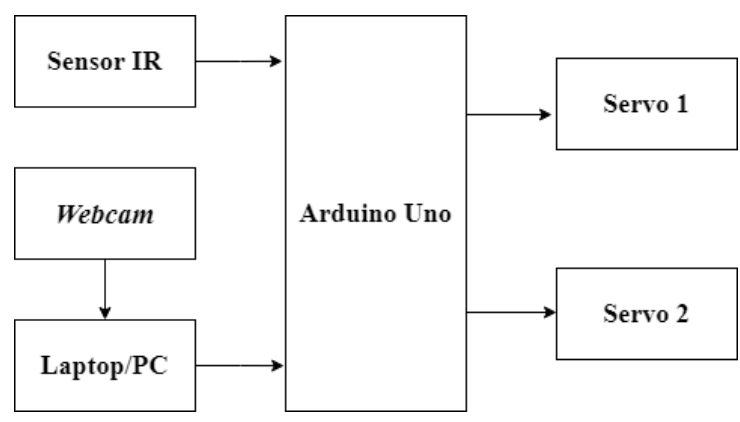

Gambar 6 . Blog Diagram

Berikut adalah fungsi dari masing masing blok diagram :

1) Webcam berfungsi sebagai sensor yang akan menditeksi benda yang akan di sortir.

2) Python adalah bahasa pemrograman yang digunakan untuk pengolahan data benda yang ditangkap oleh webcam dengan mendeteksi benda berdasarkan warna, bentuk, dan ukuran benda.

3) Laptop/Komputer sebagai media pengolahan data yang diambil oleh webcam menggunakan bahasa pemrograman Python.

4) Arduino Uno berfungsi sebagai controller system deteksi adanya benda oleh IR, motor servo1, dan motor servo2.

5) Sensor IR berfungsi untuk mendeteksi adanya benda yang akan di sortir.

6) Motor servo 1 berfungsi sebagai aktuator pemindah benda yang akan di deteksi.

7) Motor servo 2 berfungsi sebagai pembuka jalur untuk mememisahkan benda yang sudah si deteksi oleh sistem.

\section{Perancangan Perangkat Keras}

Berikut komponen elektronika apa saja yang digunakan :

1) Webcam

2) Arduino Uno

3) Senso IR

4) Motor servo

Adapun mekanik perancangan alat sesuai dengan gambar dibawah ini.

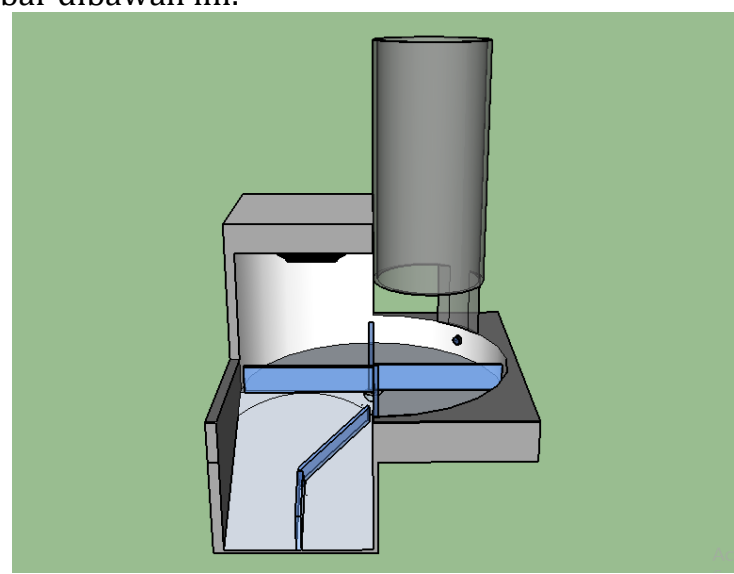

Gambar 7. Mekanik Alat

Alat ini dirancang dengan panjang dan lebar keseluruhan $\pm 35 \times 35 \times 45 \mathrm{~cm}$, dengan webcam yang ada pada gerbang $\pm 18 \times 18 \mathrm{~cm}$ yang terletak sebelah tabung penampunngan yang mampu menampung $\pm 4-5$ benda, dan lengan putar yang digerakkan dangan motorservo $360^{\circ}$, dan satu lengan pemisah yang digerakkan dengan motor servo $180^{\circ}$.

Dalam pengujian alat ini menggunakan 8 objek benda yang berbeda. Adapun klasifikasi benda yang akan diuji dapat dilihat pada tabel 1.

Tabel 1. Klasifikasi Benda Yang Akan Diuji

\begin{tabular}{cccccc}
\hline No & Objek & Warna & Bentuk & Ukuran & Hasil \\
\hline$\underline{1}$ & Benda1 & Merah & Persegi & $\underline{7 \times 7 \mathrm{~cm}}$ & $\underline{\text { Diterima }}$ \\
\hline 2 & Benda2 & Biru & Persegi & $7 \times 7 \mathrm{~cm}$ & Reject \\
\hline 3 & Benda3 & Merah & Persegi & $6 \times 6 \mathrm{~cm}$ & Reject \\
\hline 4 & Benda4 & Biru & Persegi & $6 \times 6 \mathrm{~cm}$ & Reject \\
\hline 5 & Benda5 & Merah & Lingkaran & $7 \times 7 \mathrm{~cm}$ & Reject \\
\hline 6 & Benda6 & Biru & Lingkaran & $7 \times 7 \mathrm{~cm}$ & Reject \\
\hline 7 & Benda7 & Merah & Lingkaran & $6 \times 6 \mathrm{~cm}$ & Reject \\
\hline 8 & Benda8 & Biru & Lingkaran & $6 \times 6 \mathrm{~cm}$ & Reject \\
\hline
\end{tabular}

\section{Prinsip Kerja Alat}

Cara kerja alat ini dimulai dari adanya benda yang dijatuhkan dari tempat penampungan, dan dideteksi oleh sensor IR, setelah itu benda di dorong oleh motor servo1 ke tempat pendeteksian oleh webcam, lalu gambar yang 
ditangkap oleh webcam akan di proses dengan pemrograman PYTHON, dimana benda tersebut akan dikenali warna, bentuk dan ukurannya dengan berbagai proses.

Proses pertama adalah pengenalan warna benda melalui proses segmentasi HSV, dimana range warna yang diproses adalah warna merah, jika warna benda tersebut berada di range warna merah maka benda tersebut akan terdeteksi, dan dilanjutkan dengan proses thresholding, yaitu teknik segmentasi untuk merubah warna RGB kedalam warna biner, setelah itu dilakukan proses untuk mengetahui garis tepi benda dengan menggambarkan kontur untuk mendeteksi tepi-tepi objek di dalam citra tersebut, dan proses terakhir adalah menggambarkan mid point pada masing masing garis kontur untuk mengetahui ukuran dari benda tersebut, jika benda sesuai dengan spesifikasi, maka benda tersebut akan di dorong kembali oleh servo 1 sehingga meluncur dijalur kiri, tetapi jika benda tidak sesuai maka motor servo 2 akan membuka jalur sebelah kanan, sehingga benda reject tersebut jatuh ketempat pembuangan.

Range warna yang di deteksi oleh alat ini adalah benda dengan warna merah, jika benda berwarna merah, maka benda tersebut akan diproses untuk pendeteksian bentuk dan ukuran, tetapi jika benda bukan berwarna merah maka benda akan dianggap benda reject tanpa di deteksi bentuk dan ukurannya.

\section{Rangkaian Elekronika}

Rangkaian elektronika adalah rangkaian dari komponen elektronika yang digunakan dalam alat ini, alat menggunakan komponen elektronika seperti motor servo dan sensor IR sebagai pengontrolan benda yang akan dideteksi. Dimana motor servo berfungsi sebagai actuator pendorong benda dan pemisah benda, dan sensor IR sebagai pengindraan adanya benda pada alat yang akan di deteksi.

Adapun rangkaian elektronika dalam alat ini adalah seperti gambar dibawah ini.

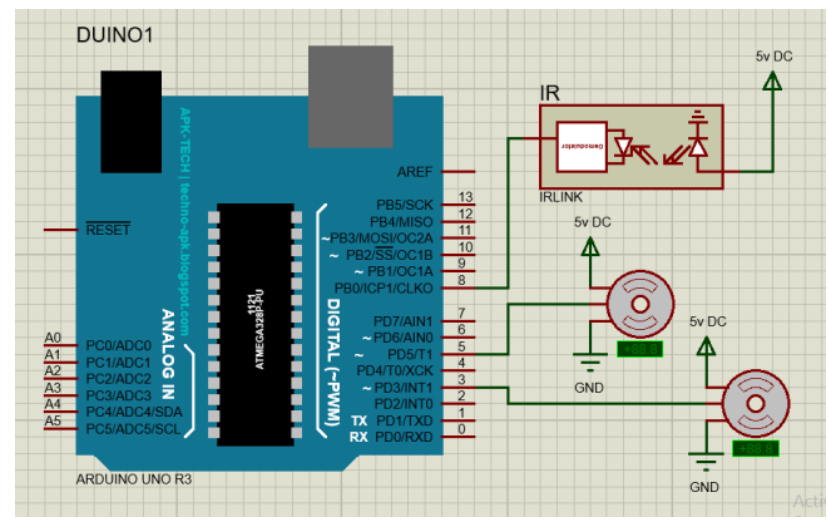

Gambar 8. Rangkaian Elektronika

\section{Flowchart Sistem}

Berikut ini adalah flowchart dari system alat ini, bertujuan agar pembaca dapat memahami system kerja dan langkah kerja dari alat yang penulis buat, adapun flowchart alat ini dapat dilihat pada gambar dibawah ini.

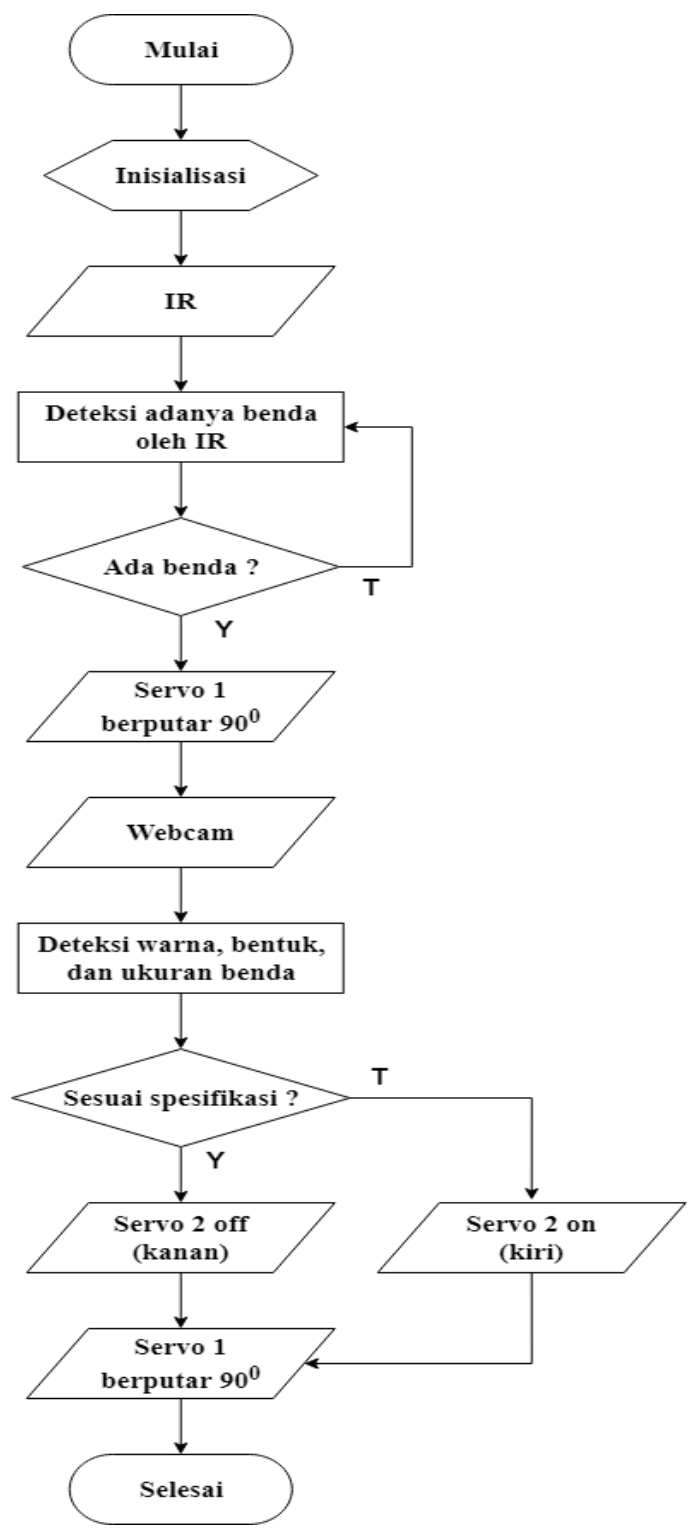

Gambar 9. Flowchar

\section{HASIL DAN PEMBAHASAN}

Berikut beberapa pengujian yang dilakukan dalam tugas akhir ini, pengujian ini dilakukan beberapakali percobaan untuk mendapatkan data-data dan bukti-bukti yang dapat di analisa terhadap proses kinerja alat.

Dalam pengujian alat ini menggunakan 8 objek benda yang berbeda, klasifikasi benda yang akan diuji ini dapat dilihat pada table 2 . 


\section{Deteksi Adanya Benda}

Pendeteksian adanya benda ini menggunakan sensor IR, adapun hasil pengujiannya adalah sebagai berikut.

Tabel 2. Pendeteksi Adanya Benda

\begin{tabular}{|c|c|c|c|}
\hline NO & Percobaan & Terdeteksi & $\begin{array}{c}\text { Tidak } \\
\text { terdeteksi }\end{array}$ \\
\hline 1 & Benda1 & $\sqrt{ }$ & \\
\hline 2 & Benda 2 & $\sqrt{ }$ & \\
\hline 3 & Benda 3 & $\sqrt{ }$ & \\
\hline 4 & Benda 4 & $\sqrt{ }$ & \\
\hline 5 & Benda 5 & $\sqrt{ }$ & \\
\hline 6 & Benda 6 & $\sqrt{ }$ & \\
\hline 7 & Benda 7 & $\sqrt{ }$ & \\
\hline 8 & Benda 8 & $\sqrt{ }$ & \\
\hline
\end{tabular}

Dari 8 kali percobaan dengan benda yang berbeda, System deteksi adanya benda ini dapat bekerja dengan baik, dimana sensor dapat mendeteksi adanya benda.

\section{Motor Servo 1}

Motor servo1 ini berfungsi untuk mendorong benda yang akan dideteksi dari tempat penampungan ke tempat pendeteksian dan tempat pemisahan benda sesuai klasifikasi ataupun tidak, tabel pengujian dapat dilihat pada tabel 3 .

Tabel 3. Pengujian Motor servo 1

\begin{tabular}{cccc}
\hline NO & Arah & Derajat & Hasil \\
\hline 1 & Kiri & $90^{\circ}$ & $\sqrt{ }$ \\
\hline 2 & Kiri & $90^{\circ}$ & $\sqrt{ }$ \\
\hline
\end{tabular}

Motor servo1 bekerja dengan baik dan sesuai dengan program, dalam 1 siklus pendeteksian benda motor sevo1 begerak $2 \times 90^{\circ}$.

\section{Motor Servo2}

Motor servo2 ini berfungsi untuk membuka jalur untuk benda yang sesuai spesifikasi ataupun tidak, hasil dari pengujian ini dapat dilihat pada tabel 4 .

Tabel 4. Pengujian Motor servo 2

\begin{tabular}{cccc}
\hline NO & Arah & Derajat & Hasil \\
\hline 1 & Kanan & $90^{\circ}$ & $\sqrt{ }$ \\
\hline 2 & Kiri & $90^{\circ}$ & $\sqrt{ }$ \\
\hline
\end{tabular}

Hasil dari table diatas, motor servo2 bekerja dengan baik dan benar, saat benda sesuai dengan spesifikasi servo2 membuka jalur kanan, dan saat benda reject servo2 membuka jalur kiri.

\section{Deteksi Warna}

Deteksian warna dalam tugas akhir ini adalah berdasarkan rentang nilai HSV yang sudah di tentukan Hasil dari pengujian deteksi warna ini dapat dilihat pada table 5 .

Tabel 5. Pengujian deteksi warna

\begin{tabular}{cccc}
\hline No & Percobaan & Terdeteksi & $\begin{array}{c}\text { Tidak } \\
\text { terdeteksi }\end{array}$ \\
\hline 1 & Benda 1 & $\sqrt{ }$ & \\
\hline 2 & Benda 2 & & $\sqrt{ }$ \\
\hline 3 & Benda 3 & $\sqrt{ }$ & \\
\hline 4 & Benda 4 & & $\sqrt{ }$ \\
\hline 5 & Benda 5 & $\sqrt{ }$ & \\
\hline 6 & Benda 6 & & $\sqrt{ }$ \\
\hline 7 & Benda 7 & $\sqrt{ }$ & \\
\hline 8 & Benda 8 & & $\sqrt{ }$ \\
\hline
\end{tabular}

Setelah dilakukan pengujian, pengenalan warna ini bekerja dengan baik, karena benda berwarna merah terdeteksi dan dapat di proses.

\section{Deteksi Bentuk}

Setelah deteksi warna, selanjutnya proses pengenalan bentuk, dalam sistem alat ini hanya dapat mengenali benda persegi. Hasil pengujian dapat dilihat pada tabel 6 .

Tabel 6. Pengujian deteksi bentuk

\begin{tabular}{ccc}
\hline No & Objek & Bentuk \\
\hline 1 & Benda 1 & Persegi \\
\hline 2 & Benda 2 & - \\
\hline 3 & Benda 3 & Persegi \\
\hline 4 & Benda 4 & - \\
\hline 5 & Benda 5 & - \\
\hline 6 & Benda 6 & - \\
\hline 7 & Benda 7 & - \\
\hline 8 & Benda 8 & - \\
\hline
\end{tabular}


Dari pengujian yang sudah dilakukan dapat dilihat pengujian pengenalan bentuk benda dapat bekerja dengan baik, benda yang dapat menjalankan proses selanjutnya hanya benda berwarna merah, jadi benda yang terdeteksi persegi hanya benda 1 dan 3 .

\section{Pengujian deteksi ukuran}

Dalam proses pendeteksian benda yang terakhir adalah ukuran benda, setelah diketahui warna dan bentuk, selanjutnya adalah pengujian ukuran benda, benda yang sesuai dengan klasifikasi adalah $7 \times 7 \mathrm{~cm}$ dengan toleransi $0,2 \mathrm{~cm}$. table pengujiannya adalah sebagai berikut.

Tabel 7. Pengujian deteksi ukuran

\begin{tabular}{ccc}
\hline No & Percobaan & Ukuran \\
\hline 1 & Benda 1 & $7,0 \times 7,1 \mathrm{~cm}$ \\
\hline 2 & Benda 2 & - \\
\hline 3 & Benda 3 & $6,0 \times 6,2 \mathrm{~cm}$ \\
\hline 4 & Benda 4 & - \\
\hline 5 & Benda 5 & $7,0 \times 6,9 \mathrm{~cm}$ \\
\hline 6 & Benda 6 & - \\
\hline 7 & Benda 7 & $5,9 \times 6,0 \mathrm{~cm}$ \\
\hline 8 & Benda 8 & - \\
\hline
\end{tabular}

Sama seperti pengujian bentuk benda sebelumnya, yang di proses dalam pengujian ukuran benda ini hanya benda yang berwarna merah, jadi pengenalan ukuran benda ini dapat bekerja dengan baik.

\section{PENUTUP}

Berdasarkan penelitian dan pengujian yang penulis kerjakan dari tugas akhir ini, dapat disimpulkan bahwa alat ini dapat bekerja dengan baik sesuai dengan yang diinginkan, karna dalam pengujiannya semua komponen ini dapat bekerja sesuai dengan system yang sudah di tentukan.

Dalam pengujian kerjanya, alat ini mampu mendeteksi adanya benda pada tempat penampungan dan memisahkan benda sesuai dengan klsifikasi yang sudah ditentukan.

Pengujian ini menggunakan 8 benda yang sudah disiapkan dimana warna, bentuk, dan ukurannya berbeda satu sama lain, dan sudah dilakukan beberapa kali pengujian, dan sangat kecil terjadinya kesalahan, baik kesalahan pengenalan benda oleh webcam ataupun pengujian yang lainnya.

\section{REFERENSI}

[1] Y. P. Prayitno And M. C. W. Harianto, "Rancang Bangun Aplikasi Pendeteksi Bentuk Dan Warna Benda Pada Mobile Robot Berbasis Webcam." Stikom Surabaya, 2011.

[2] J. Juliando And Z. Husin, "Rancang Bangun Alat Penyortir Minuman Kaleng Menggunakan Camera Dan Deteksi Warna." Sriwijaya University, 2019.

[3] R. H. Hutabarat, S. R. Sulistyanti, And E. Nasrullah, "Rancang Bangun Konveyor Penyortiran Barang Dengan Pengenalan Pola Bentuk Dan Warna Menggunakan Webcam," Electrician, Vol. 7, No. 2, Pp. 73-77, 2013.

[4] N. B. Daud, "Application Of Colors Sensor In An Automated System," Tech. Univ. Malaysia, 2007.

[5] F. Yulian And Z. M. Mayasari, "Pengembangan Teknik Pengolahan Dan Analisis Citra Penginderaan Jauh Melalui Perancangan Tapis Morfologi Matematik."

[6] H. Zarwani, "Rancang Bangun Alat Penyortir Buah Tomat Berdasarkan Ukuran Dan Warna Menggunakan Metode Segmentasi Hsv Berbasis Raspberry Pi 3b+," 2019.

[7] E. D. Handoyo, "Perancangan Mini Image Editor Versi 1.0 Sebagai Aplikasi Penunjang Mata Kuliah Digital Image Processing," J. Tek. Inform. Dan Sist. Inf., Vol. 2, No. 2, P. 219230, 2006.

[8] C. V.-B. M. Pc, "Computare Vision Berbasis Camera Dan Mini Pc Untuk Identifikasi Kecacatan Penutup Kemasan Minuman Kaleng Computare Vision-Based Mini Pc And Camera In Identifying Defective Packaging Closures Of Beverage Cans."

\section{Biodata Penulis}

Ali Basrah Pulungan, dilahirkan di Hutanaingkan, 12 Desember 1974. Menyelesaikan Studi S1 di Jurusan Teknik Elektro Universitas Sumatera Utara (USU). Pendidikan S2 Bidang Teknik Tenaga Listrik di Universitas Gajah Mada (UGM) tahun 2007. Sekarang menjadi staf pengajar di Jurusan Teknik Elektro Universitas Negeri Padang.

Zhafranul Nafis, dilahirkan di padang, 19 Juli 1997, menyelesaikan Program Study DIV Teknik Elektro Industri pada jurusan Teknik Elektro Fakultas Teknik Universitas Negeri Padang. 